\title{
Association between women's self-diagnosis of labor and labor duration after admission
}

\author{
Mechthild M. Gross ${ }^{1, *}$, Antje Petersen ${ }^{1}$, Ursula Hille ${ }^{1}$ \\ and Peter Hillemanns ${ }^{2}$ \\ ${ }^{1}$ Department of Obstetrics, Gynecology and Reproductive \\ Medicine, Midwifery Research Unit, Hannover Medical \\ School, Germany \\ ${ }^{2}$ Department of Obstetrics, Gynecology and Reproductive \\ Medicine, Hannover Medical School, Germany
}

\begin{abstract}
Aims: To examine the association between women's perception of onset and the duration of labor after hospital admission.

Methods: Women whose labor started spontaneously at term, delivering at the Hannover Medical School Hospital, Germany, between 2001 and 2004 were asked when and how labor had started. Answers were analyzed using structured content analysis. Women's symptoms were grouped in eight predefined categories; inter-rater agreement was assessed $(\kappa=0.93)$. Associations between women's symptoms and labor duration after admission were also analyzed.

Results: Duration of labor after admission was longer in nulliparas $(n=347)$ than in multiparas $(n=304, P<0.001)$. Nulliparas experienced shorter labor in association with recurrent pain, advanced cervical dilatation at admission and spontaneous rupture of membranes. Oxytocin augmentation and epidural analgesia were associated with a longer duration. In multiparas, advanced cervical dilatation at admission, spontaneously ruptured membranes, blood-tinged mucus or emotional upheaval perceived by women were associated with a shorter interval from admission until birth.

Conclusions: How women diagnose their onset of labor relates to some extent with labor duration after admission. Recognized symptoms and their association with labor duration differed between nulliparas and multiparas.
\end{abstract}

Keywords: Cox regression; multiparas; pregnancy; selfdiagnosis; spontaneous.

\footnotetext{
*Corresponding author:

Dr. Mechthild M. Gross

Department of Obstetrics,

Gynecology and Reproductive Medicine

Head of Midwifery Research Unit

Hannover Medical School

Carl-Neuberg-Str. 1

30625 Hannover

Germany

Tel.: +49-511-532-6116

Mobile: +49-172-2440157

Fax: +49-511-532-6191

E-mail: Gross.Mechthild@MH-Hannover.de
}

\section{Introduction}

The onset of labor is an important event in a woman's pregnancy, which she usually diagnoses herself. This is, of course, subject to confirmation by a midwife that labor has commenced. There are few observations regarding how women make this diagnosis and whether it affects labor duration $[3,6]$. Labor duration has frequently been defined as the interval from admission until birth $[2,18]$. In this respect, cervical dilatation at admission is a reliable proxy for the dynamics of labor at admission and thereafter [7, 9, 18]. In the study of Holmes et al. [9], 11.5\% of women seeking admission were initially sent home again, but all were subsequently admitted, on average about $12.5 \mathrm{~h}$ after the initial deferral. Over $10 \%$ of women self-admitted in labor at term were considered mistaken in their diagnosis [15]. Nearly half were in active labor within $24 \mathrm{~h}$ thereafter [15], an observation that questions the meaning of a "mistaken" diagnosis [12].

Several randomized controlled trials investigated interventions before admission. They compared between telephone advice and a home visit during early labor [10, 11], between several structured early labor assessment programs and standard care $[1,8,14]$, or between a home visit and standard care [19]. All these studies aimed at optimizing care during early labor before admission or the timing of admission itself. Further objectives were to test the influence of mode of care on the need for intrapartum interventions after admission, the duration of the remaining labor and/or the mode of birth. Although such an influence could not be significantly confirmed, these studies have probably contributed to promoting care during early labor that is better focused on the needs of the laboring women. Two small studies [10, 14] successfully achieved lower cesarean section rates and fewer intrapartum interventions. These recent results indicate that no sound knowledge exists about which factors related to the onset of labor are important to the time after admission.

In previous studies, we found that women perceived the onset of labor in various ways which, in turn, were associated to different extents with labor and care during labor $[3,5$, 6]. It is known that women's self-diagnosis of labor and admittance to hospital do not invariably coincide [3]. We therefore examined whether the way in which women diagnose the onset of labor is associated with the duration of labor after hospital admission.

\section{Subjects and methods}

Between August 2001 and February 2004 low-risk women with spontaneous labor at term and with a singleton infant in cephalic 
presentation who intended to give birth at the obstetrical unit at Hannover Medical School were asked to participate. The study was approved by the Institution's Ethical Committee.

Institutional admission policy is that women with contractions should be admitted when they are unable to cope with them on their own. Women were requested to write down when labor had started and which signs or symptoms they recognized at that point in time. The women's qualitative answers were analyzed in accordance with established methods of structured content analysis [13, 20]. The written material was divided into meaning units, each meaning unit being a sentence, a phrase, or an expression containing a single item of content. In content analysis, the sample size no longer relates to the number of participants - except for purposes of comparison but to the number of encoded meaning units. These meaning units were then assigned by two midwives to one of the following eight predefined categories: (1) recurrent pain, referring to any regular labor pains or contractions; (2) irregular pain, such as pulling, traction, or back pain; (3) watery fluid loss; (4) blood or bloody-tinged mucus; (5) gastrointestinal symptoms; (6) altered sleep patterns or sleep disturbances; (7) emotional upheaval; (8) other symptoms which were non-specific. Inter-rater reliability was high $(\kappa=0.93)$. Only 52 of 936 meaning units $(5.6 \%)$ were categorized differently between the coding midwives. These 52 units were reassessed by four experienced midwives and assigned to the category with the highest agreement.

Duration of labor was defined as the interval between admission to hospital and birth. Perinatal characteristics were extracted from patient records (Table 1). Baseline characteristics of nulliparas and multiparas were compared using the two-tailed, two sample $t$-test, Mann-Whitney $U$-test, logrank test, and $\chi^{2}$-test as appropriate for the underlying distribution. Descriptive analysis of labor duration was performed by Kaplan-Meier estimate, considering instrumental delivery and cesarean section as censored data.

Cox regression with backward elimination, using the likelihood ratio test and $\mathrm{P}>0.05$ as an elimination criterion, was used for multivariate analysis. Cox's proportional hazards model was applied, separately for nulliparas and multiparas. The hazard ratio (HR) is a measure of the acceleration or retardation, as the case may be, of the process of labor in women with a particular characteristic, such as irregular pain, as compared to women without that characteristic. A HR $>1$ means a shorter duration of labor and a HR of $<1$ a longer duration as compared to those women who did not experience that symptom. As the main aim was to evaluate the association of women's symptoms to labor duration after admission, other variables were included to control unobserved heterogeneity. Significant predictors of labor duration in the final model after backward elimination are reported in the results section. The Cox regression models were analyzed using SPSS version 14.0.

\section{Results}

The inclusion criteria were met by 347 nulliparas and 304 multiparas, representing $42 \%$ of all eligible women during the study period. Cases were censored due to operative delivery of $48(13.8 \%)$ nulliparas and $10(3.3 \%)$ multiparas. Nulliparas had a median labor duration after admission of $7.5 \mathrm{~h}$, compared with $3.2 \mathrm{~h}$ for multiparas (Figure 1; logrank: $\mathrm{P}<0.001$ ). Five hours after laborward admission only $30.2 \%$ of nulliparas had given birth, compared to no less than $68.3 \%$ multiparas.

The interval from self-diagnosis of labor to admission ranged from -13 to $126 \mathrm{~h}$ (5.3 days). Negative intervals relate to women who reported labor onset after hospital admission, mainly because they had presented themselves at hospital with ruptured membranes, which they did not consider as onset of labor. On the other hand, a few women felt themselves to be in labor several days before the baby was born. For example, one of them related her onset of labor to "severe feelings of restlessness combined with altered sleep and diarrhea, which was followed by ruptured membranes and labor pains four days later', These extremes represent the wide variation in the subjective experiences of different individuals.

Table 1 Characteristics of the 651 women participating in the study.

\begin{tabular}{|c|c|c|c|c|c|c|c|}
\hline \multirow{2}{*}{$\frac{\text { Characteristics }}{\text { Maternal age (years) (mean, SD, range) }}$} & \multicolumn{3}{|c|}{ Nulliparas $(n=347)$} & \multicolumn{3}{|c|}{ Paras $(n=304)$} & \multirow{2}{*}{$\frac{\text { P-value }}{<0.001 *}$} \\
\hline & 28.9 & 5.8 & $16-42$ & 32.1 & 5.4 & $19-44$ & \\
\hline Gestational age (days) (mean, $\mathrm{SD}$, range) & 278.3 & 8 & $259-295$ & 277.9 & 7.8 & $259-292$ & $0.46 * *$ \\
\hline Birth weight $(\mathrm{g})$ (mean, SD, range) & 3397 & 440 & $2350-4840$ & 3525 & 461 & $2450-4835$ & $<0.01 *$ \\
\hline Cervical dilatation at admission $(\mathrm{cm})$ (mean, $\mathrm{SD}$, range) & 2.6 & 2 & $0-10$ & 3.7 & 2.5 & $1-10$ & $<0.001 * *$ \\
\hline Spontaneous rupture of the membranes $(\mathrm{n}, \%)$ & 243 & 70 & & 190 & 62.5 & & $0.42 * * *$ \\
\hline Artificial rupture of the membranes (n, \%) & 104 & 30 & & 114 & 37.5 & & $0.42 * * *$ \\
\hline Epidural analgesia $(\mathrm{n}, \%)$ & 39 & 11.2 & & 7 & 2.3 & & $<0.001 * * *$ \\
\hline Oxytocin augmentation $(\mathrm{n}, \%)$ & 65 & 18.7 & & 29 & 9.5 & & $0.001 * * *$ \\
\hline $\begin{array}{l}\text { Interval from onset of labor until rupture of membranes } \\
\text { (h) (median, SD, range) })^{\mathrm{a}}\end{array}$ & 7.8 & 0.7 & $-14-135.3$ & 5.2 & 0.4 & $-12-102.2$ & $0.002 * * * *$ \\
\hline $\begin{array}{l}\text { Interval from rupture of membranes until birth }(\mathrm{h}) \\
\text { (median, } \mathrm{SD}, \text { range) }^{\mathrm{b}}\end{array}$ & 3.8 & 0.5 & $0-41.3$ & 0.9 & 0.1 & $0-23.7$ & $<0.001 * * * *$ \\
\hline 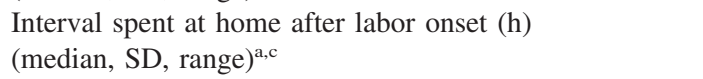 & 3.3 & 0.3 & $-7.3-126$ & 3.2 & 0.2 & $-12.9-100.3$ & $0.40 * * * *$ \\
\hline 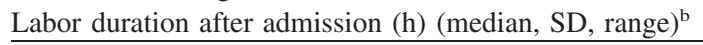 & 7.5 & 0.4 & $0.33-36.1$ & 3.2 & 0.2 & $0.05-31.5$ & $<0.001 * * * *$ \\
\hline
\end{tabular}

antervals calculated with Kaplan-Meier estimates, no censoring.

bIntervals calculated with Kaplan-Meier estimates, censoring due to operative delivery in 48 nulliparas and 10 multiparas.

'Means: 7.5 in nulliparas and 6.2 in multiparas, $\mathrm{SD}=0.86^{* * *}$.

*Two sample $t$-test; **Mann-Whitney $U$-test; $* * * \chi^{2}$-test; ****Logrank.

$\mathrm{SD}$, standard deviation. 


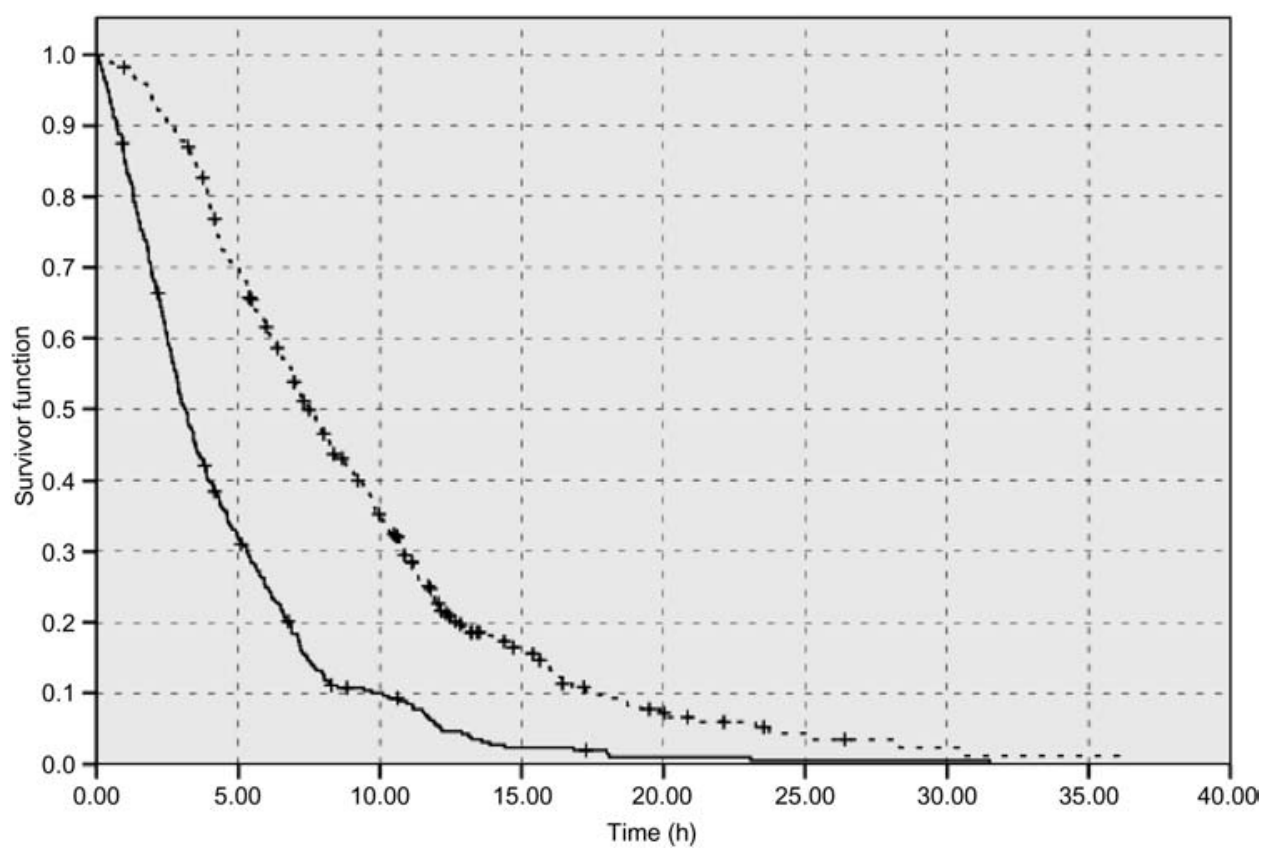

Figure 1 Kaplan-Meier estimates for the labor duration after admission in 347 nulliparas (broken line; median: 7.5 h) and 304 multiparas (continuous line; median: $3.2 \mathrm{~h}$ ); censored data are labeled with a cross.

Nulliparas and multiparas differed significantly in maternal age, birth weight, cervical dilatation at admission, augmentation with oxytocin and epidural analgesia, but not in the interval between self-diagnosis of labor and admission to hospital (Table 1). Nulliparas tended to have more spontaneous ruptures of the membranes compared to multiparas $(\mathrm{P}=0.42)$.

Among the symptoms of labor onset, $59.3 \%$ of all sampling units related to recurrent or non-recurrent forms of pain and $16.5 \%$ to watery fluid loss. Results of the Cox regression models for nulliparas (Table 2) and multiparas (Table 3) are presented in two steps. The results of the first step include all the covariates. In the final model only those factors that remain after backward elimination are presented. In the Cox regression model, there was a tendency in the final model $(\mathrm{P}=0.05)$, but not in the initial model, for labor duration to be reduced in nulliparas whose self-diagnosis included recurrent pain. To illustrate this later finding, we calculated the median duration of labor in a sample, created as an example, of nulliparas with and without recurrent pain as a symptom and with one centimeter cervical dilatation at admission and no interventions during labor. These calculations were based

Table 2 Hazard ratios (HR) for duration of labor after hospital admission in 347 nulliparas (Cox regression model).

\begin{tabular}{|c|c|c|c|c|}
\hline \multirow[t]{2}{*}{ Characteristics } & \multicolumn{2}{|c|}{ First step } & \multicolumn{2}{|c|}{ Final model } \\
\hline & HR & P-value & HR & P-value \\
\hline Maternal age (years) & 1.004 & 0.754 & & \\
\hline Gestational age (days) & 0.996 & 0.628 & & \\
\hline Birth weight $(\mathrm{g})$ & 1.000 & 0.205 & 1.000 & 0.078 \\
\hline \multicolumn{5}{|c|}{ Women's symptoms of labor onset (number of meaning units)* } \\
\hline Recurrent pain $(\mathrm{n}=200)$ & 1.306 & 0.076 & 1.286 & 0.05 \\
\hline Irregular pain $(\mathrm{n}=83)$ & 1.143 & 0.400 & & \\
\hline Watery fluid loss $(\mathrm{n}=96)$ & 0.856 & 0.422 & & \\
\hline Bloody show $(\mathrm{n}=56)$ & 1.150 & 0.410 & & \\
\hline Gastrointestinal symptoms $(\mathrm{n}=21)$ & 0.708 & 0.199 & & \\
\hline Sleep alterations $(n=14)$ & 1.000 & 1.000 & & \\
\hline Emotional upheaval $(\mathrm{n}=22)$ & 0.976 & 0.926 & & \\
\hline Timing of ruptured membranes & 1.834 & $<0.001$ & 1.538 & 0.002 \\
\hline Spontaneous vs. artificial rupture of the membranes & 0.630 & 0.002 & 0.625 & 0.001 \\
\hline Cervical dilatation on admission & 1.710 & $<0.001$ & 1.703 & $<0.001$ \\
\hline Epidural analgesia & 0.338 & $<0.001$ & 0.354 & $<0.001$ \\
\hline Oxytocin augmentation & 0.552 & 0.001 & 0.561 & $<0.001$ \\
\hline
\end{tabular}

*Numbers in brackets refer to the number of meaning units obtained from the 347 nulliparas. 
Table 3 Hazard ratios (HR) for duration of labor after hospital admission in 304 multiparas (Cox regression model).

\begin{tabular}{|c|c|c|c|c|}
\hline \multirow[t]{2}{*}{ Characteristics } & \multicolumn{2}{|c|}{ First step } & \multicolumn{2}{|c|}{ Final model } \\
\hline & HR & P-value & HR & P-value \\
\hline Maternal age (years) & 0.982 & 0.114 & & \\
\hline Gestational age (days) & 1.006 & 0.483 & & \\
\hline Birth weight $(\mathrm{g})$ & 1.000 & 0.569 & & \\
\hline \multicolumn{5}{|c|}{ Women's symptoms of labor onset (number of meaning units)* } \\
\hline Recurrent pain $(\mathrm{n}=200)$ & 0.883 & 0.439 & & \\
\hline Irregular pain $(\mathrm{n}=72)$ & 1.019 & 0.911 & & \\
\hline Watery fluid loss $(\mathrm{n}=58)$ & 0.723 & 0.133 & & \\
\hline Bloody show $(n=46)$ & 1.396 & 0.059 & 1.398 & 0.044 \\
\hline Gastrointestinal symptoms $(n=7)$ & 1.004 & 0.993 & & \\
\hline Sleep alterations $(\mathrm{n}=11)$ & 0.956 & 0.893 & & \\
\hline Emotional upheaval $(\mathrm{n}=23)$ & 1.510 & 0.086 & 1.609 & 0.032 \\
\hline \multicolumn{5}{|l|}{ Other symptoms $(\mathrm{n}=12)$} \\
\hline Timing of ruptured membranes & 1.275 & 0.140 & & \\
\hline Spontaneous vs. artificial rupture of the membranes & 0.702 & 0.011 & 0.754 & 0.028 \\
\hline Cervical dilatation on admission & 1.570 & $<0.001$ & 1.553 & $<0.001$ \\
\hline Epidural analgesia & 0.858 & 0.745 & & \\
\hline Oxytocin augmentation & 0.500 & 0.001 & 0.492 & 0.001 \\
\hline
\end{tabular}

*Numbers in parentheses refer to the number of meaning units obtained from the 304 multiparas.

on the estimated HRs of the Cox model. Other factors which did not show up as being significant in the final model were not specified. The median labor duration was $6.98 \mathrm{~h}$ without and $6.40 \mathrm{~h}$ with recurrent pain. No significant correlation could be found in nulliparas for any other of the symptoms reported (Table 2).

Results in multiparas differed from those observed in nulliparas. Multiparas who included bloody-tinged mucus $(\mathrm{P}=0.044)$ and emotional upheaval $(\mathrm{P}=0.032)$ in their selfdiagnosis of labor had a shorter labor after admission than those who did not (Table 3). This was relevant in the final model but not in the unadjusted model. As an example, median duration of labor was calculated for multiparas with $3 \mathrm{~cm}$ cervical dilatation at admission and without intrapartum interventions. Median labor duration was $3.28 \mathrm{~h}$ without bloody-tinged mucus or emotional upheaval at the women's onset of labor. When multiparas described bloody-tinged mucus, median labor duration was $2.73 \mathrm{~h}$; when they experienced emotional upheaval, median labor duration was $2.58 \mathrm{~h}$. Other symptoms of labor onset showed no significant correlation.

Advanced cervical dilatation at admission had a marked shortening effect on labor duration after admission $(\mathrm{P}<0.001)$ in both nulliparas and multiparas. Epidural analgesia was associated with a significantly longer labor duration in hospital in nulliparas $(\mathrm{P}<0.001)$ but not in multiparas. Augmentation with oxytocin was linked with a significantly longer labor duration $(\mathrm{P} \leq 0.001)$ in both nulliparas and multiparas. Spontaneous rupture of membranes was associated with a shorter duration from admission until birth compared to the labor duration of women who had an amniotomy. This effect was stronger in nulliparas $(P=0.001)$ than in multiparas $(\mathrm{P}=0.028)$. Regardless of whether membranes were ruptured artificially or spontaneously, labor was accelerated from ruptured membranes onwards in nulliparas but not in multiparas. Anamnestic factors, such as maternal age, gestational age and birth weight showed no significant associations with labor duration after admission.

\section{Discussion}

We aimed to examine whether women's own assessments of the time and type of their onset of labor ("Geburtsbeginn") might provide predictors for the time spent in hospital during labor above the traditional parameters, such as cervical dilatation at admission. Nevertheless, the way in which women described their onset of labor was far less closely associated with the duration of labor after admission than we had anticipated. The birth processes of nulliparas who indicated recurrent pains as marking the onset of labor tended to be associated with a shorter interval from hospital admission until birth as compared to those women who did not report this symptom. In multiparas, blood-tinged mucus and emotional upheaval were also associated with a shorter interval between admission and birth. Other signs and symptoms, including irregular pain, gastrointestinal symptoms, altered sleep patterns and self-diagnosed watery fluid loss may all be relevant in terms of the transition from pregnancy to childbirth and a woman's recognition of the onset of labor [5] or her reason for coming to hospital [3], but they are irrelevant in terms of the duration of labor after arrival in hospital.

Limitations of our study include the fact that the convenient sample falls short of being representative for all the women in labor. In addition, we have to address the fact that using prospective information as well as data from perinatal records may have caused inhomogeneity with data analysis. Another limitation of our study relates to the fact that we used intrapartum interventions in a time-constant manner. 
Therefore, associations with the duration from admission until birth have to be interpreted with caution. Intrapartum interventions are used without precise reference to when they occur during the process of labor.

So far, the optimum timing of admission remains an unsolved issue $[1,8,12-14,19]$. One small randomized study [14] was able to demonstrate that women who are admitted at an advanced stage of labor benefit from experiencing fewer interventions or unwanted outcomes than those who were admitted earlier. Since this study was published, women have been advised to cope with labor as long as possible on their own. On the other hand, there are an increasing number of women who feel the need to be counselled even early in labor. This might be followed by more monitoring sessions and consequently more interventions.

Our multivariate analysis was able to include the extent of cervical dilatation at the time when the women were admitted for the duration of labor as a validating factor in our model. We do know that the degree of cervical dilatation serves as a reliable proxy for the intensity of labor [7, 9], meaning the speed of labor progress which is per se hardly measurable. In addition to cervical dilatation, we identified some intrapartum factors that were associated with length of labor between admission and birth. Our study ascertained that the timing of rupture of the membranes, whether spontaneous or artificial, plays a role in labor duration in multiparas. Spontaneous rupture of membranes was associated with a shorter duration from admission onwards compared to labor duration of women who had an amniotomy. Augmentation with oxytocin was linked in both groups to significantly prolonged labor after admission. As amniotomy and augmentation with oxytocin are usually performed to activate the labor progress, it is important to note that no cause/effect relationship between amniotomy and oxytocin augmentation can be derived from the observational data presented here. This also applies to epidural analgesia, which was associated with longer labor duration in nulliparas. It was nevertheless necessary to include these interventions as covariates to check for unobserved heterogeneity. One could also regard the incidence of interventions as a proxy for a complicated labor process.

With regard to pre-existing factors, neither maternal age nor infant birth weight had a statistically significant effect on labor duration after admission. These factors are obviously more relevant for the duration of first or second stage of labor [4, 16, 17].

It was the first time to our knowledge that a Cox regression model had ever been used to predict which factors were associated with time from admission to birth. Labor duration after admission is considered as the dependent process, which implies that intrapartum interventions acquire the status of covariates. This contrasts with the treatment of intrapartum interventions after admission as outcomes, as was frequently the case in randomized trials on early labor $[1,8$, $11,19]$. This at least indicates the need for a change in the study design and might be worthy of discussion in terms of what is related to what during the childbearing process.
Overall, two main conclusions can be drawn from our study. First, the reasons for seeking labor ward admission at term and the signs that are perceived to herald the onset of labor are not necessarily the same, regardless of coinciding or being similar for nulliparas and multiparas. This applies especially to elements, such as ruptured membranes or blood loss in accord with what women have learnt in antenatal classes, irrespective of whether they themselves perceive this to be the onset of labor.

Second, although a woman's self-diagnosis of labor is of great importance, its effect on labor duration after admission at term is minimal as compared to the cervical assessment on admission. While the interval from admission until birth is not meaningful enough to be related to women's symptoms, women's symptoms obviously have a more important role with other intervals during labor [6]. Due to this observation, our data provide evidence that not only predictors and interventions but also intervals during labor have to be chosen carefully. In view of the special requirements for a longitudinal approach in childbirth research, secondary analysis of large data sets or sensitivity analyses of trial data in a time-dependent longitudinal approach might provide better evidence about what really matters to mothers and their babies during labor.

\section{Acknowledgments}

We thank the midwives Tanja Haunschild, Tina Kuesel and Viola Klaus for assistance with data categorization and Professor Emeritus Hecker for his statistical assistance with a previous version.

\section{References}

[1] Cheyne H, Hundley V, Dowding D, Bland JM, McNamee P, Greer I, et al. The effects of an algorithm for diagnosis of active labor: a cluster randomised trial. Br Med J. 2008; 337:a2396.

[2] Gross MM, Keirse MJNC. The clinical onset of labor in obstetric research. Z ärztl Fortbild Qual. 2002;96:665-70.

[3] Gross MM, Burian RA, Froemke C, Hecker H, Schippert C, Hillemanns P. Onset of labour: women's experiences and midwives' assessments in relation to first stage duration. Arch Gynecol Obstet. 2009;280:899-905.

[4] Gross MM, Drobnič S, Keirse MJNC. Influence of fixed and time-dependent variables on the duration of spontaneous first stage labor. Birth. 2005;32:27-33.

[5] Gross MM, Haunschild T, Stoexen T, Methner V, Guenter HH. Women's recognition of the spontaneous onset of labor. Birth. 2003;30:267-71.

[6] Gross MM, Hecker H, Matterne A, Guenter HH, Keirse MJNC. Does the way that women experience the onset of labor influence the duration of labor? Br J Obstet Gynecol. 2006;113:289-94.

[7] Hemminki E, Simukka R. The timing of hospital admission and progress of labor. Eur J Obstet Gynecol Reprod Biol. 1986;22:85-94. 
[8] Hodnett E, Stremler R, Willan AR, Weston JA, Lowe NK, Simpson KR, et al. Effect on birth outcomes of a formalised approach to care in hospital labor assessment units: international, randomised controlled trial. Br Med J. 2008;337: a1021.

[9] Holmes P, Oppenheimer LW, Wu Wen S. The relationship between cervical dilatation at initial presentation in labor and subsequent intervention. Br J Obstet Gynaecol. 2001;108: 1120-4.

[10] Janssen PA, Iker CE, Carty EA. Early labor assessment and support at home: a randomised controlled trial. J Obstet Gynaecol Can. 2003;25:734-41.

[11] Janssen PA, Still D, Klein MC, Singer J, Carty EA, Liston RM, et al. Early labor assessment and support at home versus telephone triage. Obstet Gynecol. 2006;108:1463-9.

[12] Keirse MJNC. A final comment ... managing the uterus, the woman, or whom? Birth. 1993;20:159-61.

[13] Krippendorf K. Content analysis. An introduction to its methodology. Beverly Hills: Sage; 2004.

[14] McNiven PS, Williams JI, Hodnett E, Kaufman K, Hannah ME. An early labor assessment program: a randomized controlled trial. Birth. 1998;25:5-10.

[15] O'Driscoll K, Stronge JM, Minogue M. Active management of labor. Br Med J. 1973;3:135-40.
[16] Paterson CM, Saunders NSG, Wadsworth J. The characteristics of the second stage of labor in 25069 singleton deliveries in the North West Thames Health Region, 1988. Br J Obstet Gynaecol. 1992;99:377-80.

[17] Rasmussen S, Bungum L, Hoie K. Maternal age and duration of labor. Acta Obstet Gynecol Scand. 1994;73:231-4.

[18] Reuwer P, Bruinse H, Franz A. Proactive support of labor. The challenge of normal childbirth. Cambridge: Cambridge University Press; 2009.

[19] Spiby H, Green JMG, Renfrew MJ, Crawshaw S, Stewart P, Lishman $\mathrm{J}$, et al. Improving care at the primary/secondary interface: a trial of community-based support in early labor. The ELSA trial. Final report submitted to the National Coordinating Centre for NIHR Service Delivery and Organisation (NCCSDO), under peer review. 2008.

[20] Weber RP. Measurement models for content analysis. Quality and Quantity. 1983;17:127-49.

The authors stated that there are no conflicts of interest regarding the publication of this article.

Received February 27, 2009. Revised June 24, 2009. Accepted July 28, 2009. Previously published online December 3, 2009. 